\title{
Germinação e desenvolvimento inicial de clones de cajueiro comum sob irrigação com água salina
}

\author{
Alan B. 0. de Sousa ${ }^{1}$, Marlos A. Bezerra ${ }^{2} \&$ Fábio C. Farias ${ }^{2}$
}

\section{RESUMO}

A maioria dos pomares de cajueiro no Brasil está localizada no trópico semiárido, onde a água é escassa e apresenta problemas de salinidade. Desta forma, este trabalho objetivou avaliar o efeito da salinidade na germinação e no desenvolvimento inicial de mudas de cajueiro BRS 274 e BRS 275. Os tratamentos foram dispostos em esquema fatorial $5 \times 2 \mathrm{com}$ quatro repetições, referentes a soluções salinas ajustadas

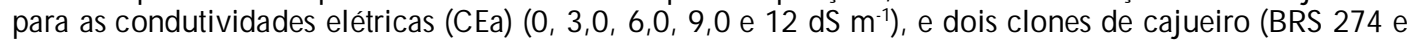
BRS 275). As variáveis avaliadas foram: porcentagem de emergência (PE), índice de velocidade de emergência (IVE), tempo médio de emergência (TM E), altura da plântula (AP), diâmetro da plântula (DP), número de folhas (N F), área foliar (AF), massa seca das folhas (M SF), massa seca do caule (M SC) e massa seca da raiz (MSR) obtidos 30 dias após a emergência. Houve efeito de interação entre os clones e a salinidade da água de irrigação para as variáveis PE e IVE. Por sua vez, todas as variáveis estudadas foram influenciadas pela salinidade da água de irrigação e o clone BRS 275 apresentou resultados superiores para as variáveis PE, IVE, TME, AF e MSF em comparação com o clone BRS 274.

Palavras-chave: Anacardium occidentale, condutividade elétrica, salinidade

\section{Germination and seedling establishment of clones of cashew irrigated with saline water}

\begin{abstract}
Most cashew orchards in Brazil are located in semi-arid tropics, where water is scarce and has salinity problems. Based on this fact, this study aimed to evaluate the effect of water salinity on initial development of clones of cashew. Treatments were arranged in a $5 \times 2$ factorial design with four replications, relative to electrical conductivity of water for irrigation (ECW) (0, 3.0, 6.0, 9.0 and $\left.12.0 \mathrm{dS} \mathrm{m}^{-1}\right)$, and two clones of cashew (BRS 274 and BRS 275). The variables evaluated were: percentage of emergence (PE), rate of emergence (IVE), mean emergence time (TME), seedling height (AP), diameter of the seedling (DP), leaf area (AF), leaf dry matter (MSF), stem dry matter (M SC) and root dry matter (M SR) obtained 30 days after emergence. There was an interaction between clones and salinity of irrigation water for the variables PE and IVE. All parameters studied were affected by salinity of irrigation water and the clone BRS 275 presented superior results for PE, IVE, TME, AF and MSF variables compared to clone BRS 274.
\end{abstract}

Key words: Anacardium occidentale, electrical conductivity, salinity

Trabalho submetido e selecionado no primeiro Simpósio Brasileiro de Salinidade realizado de 12-15/10/2010 em Fortaleza, Ceará, Brasil ${ }_{1}^{1}$ D ENA/U FC, Av. Mister Hull, 2977, Campus do Pici, CEP 60356-000, Fortaleza, CE. Fone: (85) 8786-5249. E-mail: alan2b@gmail.com 2 Embrapa Agroindústria Tropical e Instituto N acional de Ciência e Tecnologia em Salinidade (INCTSal/CN Pq), Rua D ra Sara M esquita, 2270 , Planalto do Pici, CEP 60511-110, Fortaleza, CE. Fone: (85) 3391-7220; (85) 8640-4071. E-mail: marlos@cnpat.embrapa.br; fabiocosta@yahoo.com 


\section{INTRODUÇÃO}

Dentre as espécies frutíferas cultivadas no Nordeste brasileiro o cajueiro se destaca, tanto pela área de produção que chega a mais de 730.000 ha plantados, quanto pelo potencial de exportação de suas castanhas. Grande parte desses pomares foi propagada por sementes e são cultivados sob regime de sequeiro (Barros et al., 2004), embora nos últimos anos a prática de irrigação se venha apresentando como alternativa viável para o estabelecimento de novos pomares mais produtivos (Cavalcanti Júnior \& Chaves, 2001). Como a maioria dos pomares de cajueiro no Brasil está localizada no trópico semiárido, onde a água é escassa e apresenta problemas de salinidade (Gheyi, 2000), os pomares irrigados, especialmente os viveiros de produção de mudas, são forçados a utilizar água de baixa qualidade.

Em geral, a salinidade inibe o crescimento das plantas em função dos efeitos osmóticos e tóxicos dos íons (Munns, 2002). Dentre os processos fisiológicos afetados pelo estresse salino se destacam a assimilação do $\mathrm{CO}_{2}$ e a síntese de proteínas, as quais limitam a capacidade produtiva das plantas. No caso da produção de mudas este efeito é mais pronunciado, uma vez que nesta fase as plântulas estão mais susceptíveis aos efeitos do sal.

Os mecanismos de controle da absorção, transporte e distribuição dos íons em toda a planta, assim como a capacidade de compartimentalização no vacúolo e o acúmulo de solutos orgânicos no citoplasma, permitindo o ajustamento osmótico, são importantes mecanismos de tolerância das plantas ao estresse salino (Ashraf \& Harris, 2004).

Em cajueiro anão precoce estudos evidenciam que a porcentagem de germinação só é afetada em níveis elevados de sal; no entanto, o tempo médio de emergência das plântulas é afetado, atrasando a emergência dessas plântulas (Bezerra et al., 2002; Carneiro et al., 2002). Pode-se inferir, então, que o cajueiro anão precoce é mais tolerante durante a germinação que durante as fases posteriores do desenvolvimento de plântulas (Bezerra et al., 2007).

Em função do exposto procurou-se avaliar a germinação e o desenvolvimento inicial de plântulas de cajueiro comum (clones BRS 274 e BRS 275), em ambiente protegido e irrigadas com diferentes soluções salinas, visando observar respostas diferenciadas entre os clones.

\section{MATERIAL E MÉTODOS}

$\mathrm{O}$ experimento foi conduzido em casa de vegetação da Embrapa Agroindústria Tropical Fortaleza, CE, Brasil. Sementes oriundas dos clones BRS 274 e BRS 275, tratadas previamente com fungicida sistêmico, foram semeadas em recipientes contendo $500 \mathrm{~mL}$ de vermiculita. A partir da semeadura iniciouse a aplicação dos tratamentos, que consistiu da aplicação, a cada dois dias, de $150 \mathrm{~mL}$ de solução salina, de acordo com o tratamento estabelecido.

As soluções salinas foram preparadas pela adição de diferentes quantidades de sais de $\mathrm{NaCl}, \mathrm{CaCl}_{2} \cdot 2 \mathrm{H}_{2} \mathrm{O}$ e $\mathrm{MgCl}_{2} \cdot 6 \mathrm{H}_{2} \mathrm{O}$, na proporção de $7: 2: 1$, obedecendo-se à relação entre CEa e a concentração dos sais $\left(\mathrm{mmol}_{\mathrm{c}} \mathrm{L}^{-1}=\mathrm{CE} \times 10\right)$, extraída de Rhoades et al. (1992).

Os tratamentos foram dispostos em esquema fatorial $5 \times 2$ com quatro repetições, referentes às soluções salinas ajustadas para as condutividades elétricas (CEa) $(0,3,0,6,0,9,0$ e 12,0 dS $\mathrm{m}^{-1}$ ) e dois clones de cajueiro (BRS 274 e BRS 275).

Para as variáveis de emergência foram realizadas contagens diárias para o calculo do índice de velocidade de emergência (IVE), tempo médio de emergência (TME) e porcentagem de emergência (PE) obtida 30 dias após a semeadura. Ao término do experimento foram avaliadas as variáveis: altura da plântula (AP), diâmetro da plântula (DP), número de folhas (NF), área foliar (AF), matéria seca das folhas (MSF), matéria seca do caule (MSC) e matéria seca da raiz (MSR).

O delineamento experimental utilizado foi o inteiramente casualizado com os resultados submetidos à análise de variância e de regressão, realizando-se a comparação entre as concentrações salinas e as variáveis observadas.

\section{RESULTADOS E DISCUSSÃO}

Todas as variáveis de germinação foram afetadas pela salinização da água de irrigação.

Os clones também diferiram significativamente para todas as variáveis e a interação entre o tipo de clone e a salinidade da água de irrigação foi significativa para porcentagem de emergência (PE) e índice de velocidade de emergência (IVE) (Tabela 1).

Tabela 1. Análise de variância para porcentagem de emergência (PE), índice de velocidade de emergência (IVE) e tempo médio de emergência (TME) dos clones BRS 274 e BRS 275 de cajueiro irrigado com águas de diferentes concentrações de sais (CEa)

\begin{tabular}{lcccc}
\hline \multirow{2}{*}{ F.V. } & \multirow{2}{*}{ G.L. } & \multicolumn{3}{c}{ Quadrado médio } \\
\cline { 3 - 5 } & & PE & IVE & TME \\
Salinidade (S) & 4 & $1539,9^{*}$ & $245,6^{*}$ & $112,8^{*}$ \\
Clone (C) & 1 & $10017,2^{*}$ & $1040,4^{*}$ & $55,2^{*}$ \\
SXC & 4 & $1155,9^{*}$ & $104,9^{*}$ & $3,4 \mathrm{~ns}$ \\
Residuo & 30 & 418,8 & 24,1 & 5,5 \\
CV & $(\%)$ & 34,01 & 32,32 & 10,92 \\
\hline
\end{tabular}

* Significativo a $5 \%$ de probabilidade pelo teste $\mathrm{F}$; ns - não significativos

Na Figura 1 (A e B) se observa a influência negativa da salinidade da água de irrigação sobre as variáveis PE e IVE para o clone BRS 275, enquanto para o clone BRS 274, nenhum efeito foi observado. Ressalta-se que, embora não afetados pela salinidade, a porcentagem e o índice de velocidade de emergência do BRS 274 sempre foram inferiores aos do BRS 275. Observa-se, por outro lado, para os dois clones estudados, aumento linear para o tempo médio de emergência com 4,4\%, para cada incremento unitário na $\mathrm{CEa}$ (Figura 1C). O mesmo comportamento no tempo médio de emergência foi observado por Bezerra et al. (2002); Carneiro et al. (2002), trabalhando com cajueiro anão precoce. Os últimos autores observaram um incremento de 3,89\% para cada incremento unitário na CEa. 
A.

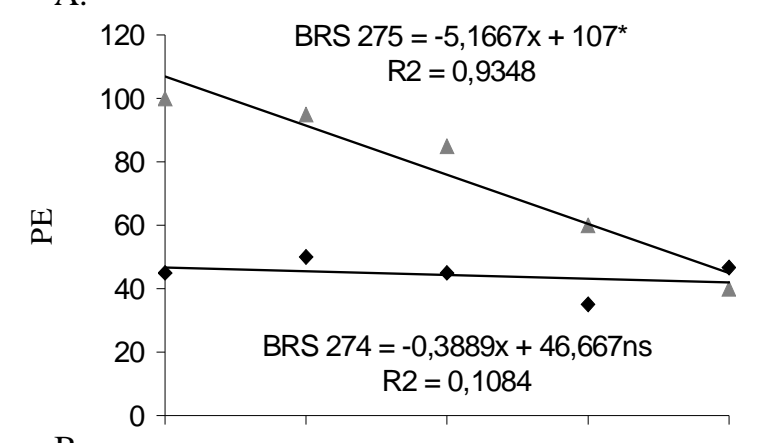

B.

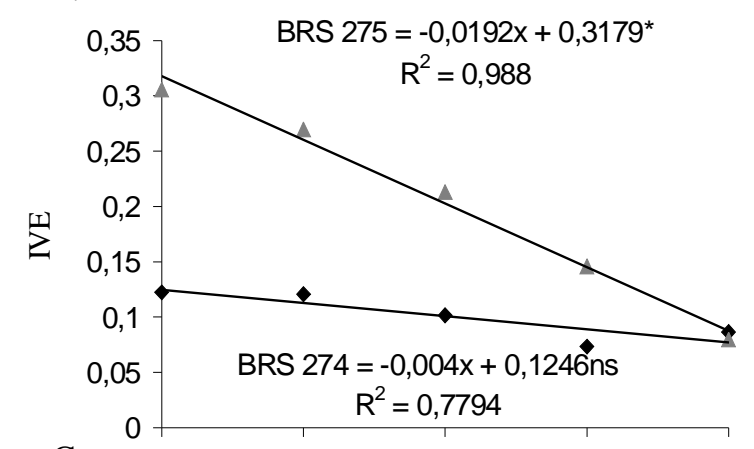

$$
\text { C. }
$$

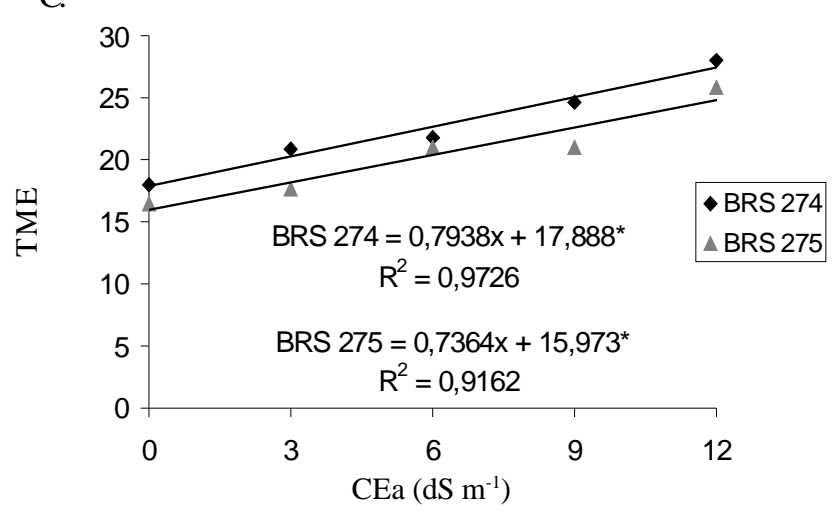

* - significativo a 0,05 de probabilidade pelo teste $F$; ns - não significativo

Figura 1. (A) porcentatagem de emergencia(PE); (B) índice de velocidade de emergência (IVE); (C) tempo médio de emergência (TM E) de sementes de cajueiro BRS 274 e BRS 275, em função da salinidade da água de irrigação (CEa)

O fator salinidade na água de irrigação influenciou todas as variáveis de crescimento estudadas. Não foram observadas diferenças significativas entre os clones para as variáveis AP, DP, MSC e MSR. Por sua vez, não houve interação entre a salinidade da água de irrigação e os clones (Tabela 2).

A salinidade da água de irrigação afetou negativamente o crescimento das plantas, sendo o efeito linear, com decréscimo relativo (comparado ao controle) para cada incremento unitário de $\mathrm{CEa}$ de 6,1, 4,1 e 6,0\% respectivamente para altura, diâmetro e área foliar (Figuras 2A, B e C). Os resultados foram semelhantes aos obtidos por Carneiro et al. (2002) que, trabalhando com genótipos de cajueiro anão precoce, obtiveram, para cada incremento unitário na CEa, decréscimo de $8,49 \%$ para altura da planta e $14,82 \%$ para área foliar. Redução no desenvolvimento da parte aérea em função da salinidade também foi observada por Rebequi et
Tabela 2. Análise de variância para altura da plântula (AP), diâmetro da plântula (DP), área foliar (AF), matéria seca das folhas (MSF), matéria seca do caule (MSC) e matéria seca da raiz (MSR) dos clones BRS 274 e BRS 275 de cajueiro irrigado com águas de diferentes concentrações de sais (CEa)

\begin{tabular}{|c|c|c|c|c|c|c|c|}
\hline \multirow{3}{*}{ F.V. } & \multirow{3}{*}{ G.L. } & \multicolumn{6}{|c|}{ Quadrado médio } \\
\hline & & \multirow{2}{*}{$\begin{array}{c}\text { AP } \\
(\mathrm{cm})\end{array}$} & \multirow{2}{*}{$\begin{array}{c}\text { DP } \\
(\mathrm{mm})\end{array}$} & \multirow{2}{*}{$\begin{array}{c}\mathrm{AF} \\
\left(\mathrm{cm}^{2}\right)\end{array}$} & MSF & MSC & MSR \\
\hline & & & & & \multicolumn{3}{|c|}{ (g) } \\
\hline Salinidade (S) & 4 & $406,7^{*}$ & $13,1^{*}$ & $112046,4 *$ & $3,9 *$ & $3,08^{*}$ & $2,47 *$ \\
\hline Clone $(\mathrm{C})$ & 1 & $7,2 \mathrm{~ns}$ & $1,2 \mathrm{~ns}$ & $33062,5^{*}$ & $0,9 *$ & $0,02 \mathrm{~ns}$ & $0,22 \mathrm{~ns}$ \\
\hline $\mathrm{SxC}$ & 4 & $8,4 \mathrm{~ns}$ & $0,4 \mathrm{~ns}$ & 3952,3 ns & $0,2 \mathrm{~ns}$ & $0,08 \mathrm{~ns}$ & $0,10 \mathrm{~ns}$ \\
\hline Resíduo & 30 & 14,0 & 1,0 & 5826,2 & 0,2 & 0,27 & 0,17 \\
\hline $\mathrm{CV}$ & (\%) & 24,5 & 22,9 & 28,0 & 35,8 & 51 & 35,6 \\
\hline
\end{tabular}

al. (2009) trabalhando com limão-cravo irrigado com águas salinas em substrato sem e com biofertilizantes bovinos. Mendonça et al. (2007), observaram queda no incremento do diâmetro de mudas de Eucalyptus pellita, Eucalyptus robusta e Eucalyptus camaldulensis, em função da condutividade elétrica do substrato.

Nas glicófitas a diminuição da área foliar é uma das respostas iniciais ao estresse osmótico resultante da salinidade, visando diminuir a perda de água por transpiração. Entretanto, tal redução na área foliar diminui a área disponível para a fotossíntese que, por sua vez seria um dos responsáveis pelo menor crescimento das plantas em condições de estresse salino (Parida et al., 2004).

As variáveis massa seca da folha, do caule e da raiz (MSF, MSC, MSR), dos clones estudados, foram afetadas negativamente pela salinidade da água de irrigação, com redução linear, em função do incremento da $\mathrm{CEa}$, na proporção de 6,5, 6,1 e 5,9\% respectivamente, para cada unidade de salinidade excedente à água utilizada no controle (Figuras 2D, E e F).

Embora as raízes apresentem maior capacidade de ajustamento osmótico, e melhor proteção do estresse oxidativo sob condições de estresse salino (Abreu et al., 2008), a redução do seu crescimento foi praticamente semelhante à redução do crescimento da parte aérea.

A supressão do crescimento inicial das plântulas de cajueiro cultivadas em condições de salinidade ocorre devido, provavelmente, à redução na disponibilidade de água ou ao acúmulo excessivo de íons $\left(\mathrm{Na}^{+}\right.$e $\left.\mathrm{Cl}^{-}\right)$nos tecidos vegetais que, por sua vez, podem afetar os processos fisiológicos, como a taxa de assimilação de $\mathrm{CO}_{2}$ (Navarro et al., 2007) e provocar desequilíbrio nutricional (Fernandes et al., 2003). Lopes et al. (2009), comentam que a redução no crescimento causado pelo estresse salino também pode estar relacionada ao gasto energético necessário para a síntese de compostos orgânicos osmoticamente ativos.

Os resultados obtidos no presente estudo parecem corroboraram a observação de Bezerra et al. (2007), trabalhando com cajueiro anão precoce, de que nesta espécie o crescimento e o desenvolvimento das plantas são mais susceptíveis à salinidade do que a fase de germinação. 
A.

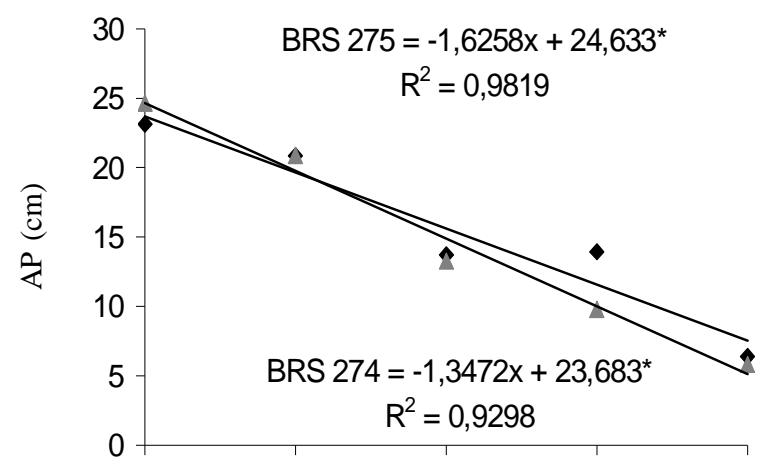

C.

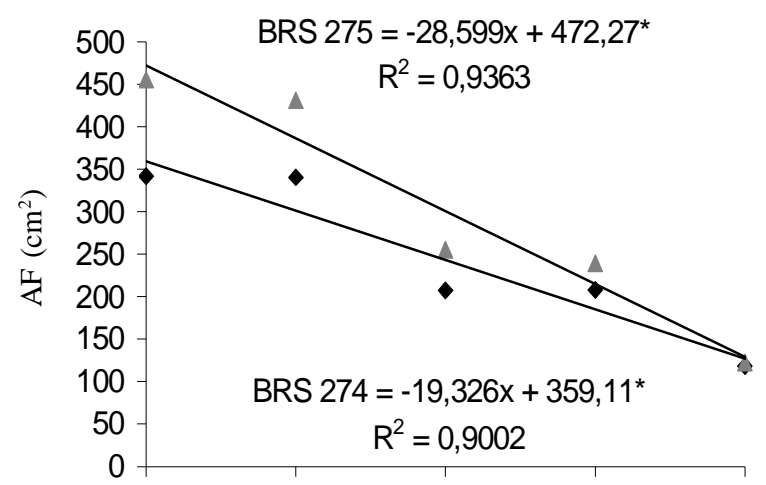

E

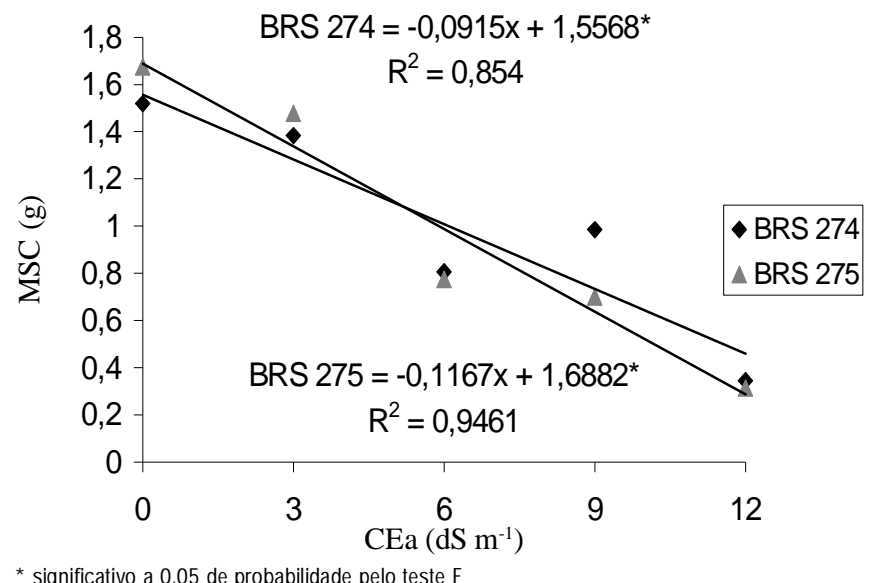

B.

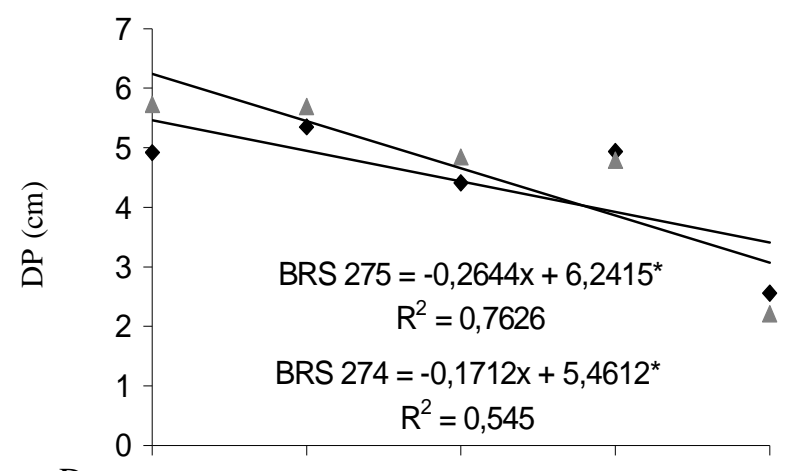

D.

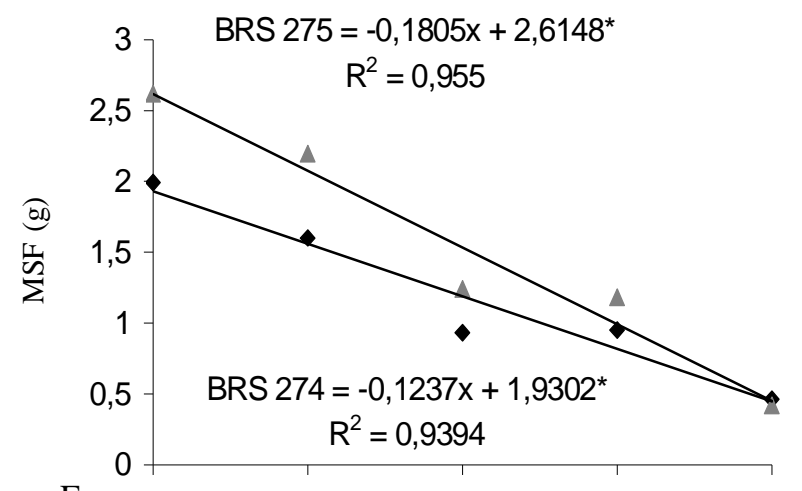

F.



Figura 2. (A) Altura da plântula (AP); (B) D iâmetro das plântulas (DP); (C) Área foliar (AF); (D) M atéria seca das fol has (MSF); (E) M atéria seca do caule (MSC); (F) M atéria seca da raiz (M SR) de plântulas de cajueiro BRS 274 e BRS 275, em função da salinidade da água de irrigação

\section{ConclusõEs}

1. O incremento da salinidade na água de irrigação afetou negativamente todas as variáveis de germinação e de crescimento inicial das plântulas de cajueiro comum.

2. Com exceção da porcentagem e índice de velocidade de emergência, os efeitos da salinidade foram os mesmos para os clones BRS 274 e BRS 275.

\section{Agradecimentos}

Ao CNPq, pela bolsa de Mestrado, e ao INCTSal, pelo financiamento da pesquisa.

\section{LITERATURA CITADA}

Abreu, C.E. B.; Prisco, J. T.; Nogueira, A. R. C.; Bezerra, M. A.; Lacerda, C. F.; Gomes Filho, E. Physiological and biochemical changes occurring in dwarf-cashew seedlings subjected to salt stress. Brazilian Journal of Plant Physiology, v.20, p.105$118,2008$.

Ashraf, M.; Harris, P. J. C. Potential biochemicalindicators of salinity tolerance in plants. Plant Science, v.166, p.889-899, 2004.

Barros, L. M.; Crisóstomo, J. R.; Paiva, W. O.; Paiva, J. R. Melhoramento genético do cajueiro. In: Silva, V. V. da. (ed.). Caju. O produtor pergunta, a Embrapa responde. Brasília: Embrapa SPI, 2004. p.81-92. 
Bezerra, I. L.; Gheyi, H. R.; Fernandes, P. D.; Santos, F. J. S.; Gurgel, M. T.; Nobre R. G. Germinação, formação de portaenxertos e enxertia de cajueiro anão-precoce sob estresse salino. Revista Brasileira de Ciências Agrárias, v.6, p.420-424, 2002.

Bezerra, M. A.; Lacerda, C. F.; Gomes-Filho, E.; Abreu, C. E. B.; Prisco, J. T., Physiology of cashew plants grown under adverse conditions. Brazilian Journal Plant Physiology, v.19, p.449-461, 2007.

Carneiro, P. T.; Fernandes, P. D.; Gheyi, H. R.; Soares, F. A. L. Germinação e crescimento inicial de genótipos de cajueiro anão-precoce em condições de salinidade. Revista Brasileira de Engenharia Agrícola e Ambiental, Campina Grande, v.6, n.2,p.199-206, 2002.

Cavalcanti Junior, A. T.; Chaves, J. C. M. Produção de mudas de cajueiro. Fortaleza: Embrapa Agroindústria Tropical, 2001. Documentos 42

Fernandes, A. R.; Carvalho, J. G.; Curi, N.; Guimarães, P. T.; Pinto, J. E. B. P. Crescimento de mudas de pupunheira (Bactris gasipaes H. B. K.) sob diferentes níveis de salinidade.Ciência Agrotécnica, Lavras, v.2, n.2, p.278-284, 2003.

Gheyi, H. J. Problemas de salinidade na agricultura irrigada. In: Oliveira, T. S.; Assis Jr, R. N.; Romero, R. E.; Silva, J. R. C. (ed.). Agricultura, sustentabilidade e o semiárido. Fortaleza: DCS/UFC, 2000. p.329-346.
Lopes, T. C.; Klar, A. E. Influência de diferentes níveis de salinidade sobre aspectos morfofisiológicos de mudas de Eucalyptus urograndis. Revista Irriga, v.14, p.68-75, 2009. Mendonça, A. V. R.; Carneiro, J. G. A.; Barroso, D. G.; Santiago, R. A.; Rodrigues, L. A.; Freitas, T. A. S. Características biométricas de mudas de Eucalyptus sp sob estresse salino. Revista Árvore, v.31, p.365-372, 2007.

Munns, R. Comparative physiology of salt and water stress. Plant Cell \& Environment, v.25, p.239-250, 2002.

Navarro, A.; Bañon, S.; Olmos, E; Sánchez-Blanco, M. J. Effects of sodium chloride on water potential components, hydraulic conductivity, gas exchange and leaf ultrastructure of Arbutus unedo plants. Plant Science, v.172, p.473-480, 2007.

Parida, A. K.; Das, A. B.; Mittra, B. Effects of salt on growth, ion accumulation, photosynthesis and leaf anatomy of the mangrove, Bruguiera parviflora. Trees, v.18, p.167-174, 2004.

Rebequi, A. M.; Cavalcante, L. F.; Nunes, J. A.; Diniz, A. A.; Brehm, M. A. S.; Cavalcante, M. Z. B. Produção de mudas de limão cravo em substrato com biofertilizante bovino irrigado com águas salinas. Revista de Ciências Agrárias, v.32, p.219-228, 2009.

Rhoades, J. P.; Kandiah, A.; Mashali, A. M. The use saline waters for crop production. Rome: FAO, 1992. 180p. 